\title{
MILLLETVEKILII GENEL SEÇIMLERINE ÇEVREDEN BAKMAK: KÜTAHYA 1960-1971
}

\section{Gökhan GÖKTÜRK ${ }^{1}$}

\section{$\ddot{\mathbf{O} z}$}

1960-1971 arası dönem Türkiye'de ideolojilerin biçimlendiği, siyasal partiler arası farkların/ayrımların arttı̆g bir sürece denk gelmektedir. 27 Mayıs askeri müdahalesi ile başlayıp 12 Mart muhtırası ile biten bu dönemde politikleşmenin had safhada olduğu görülmektedir. 1968'te yaşanan öğrenci hareketlerinin Türkiye'ye yansıması yine bu dönemde öne çıkan başlıklar arasındadır. Gerek dünya gerekse ülke gündemindeki makro gelişmelerin mikro düzlemde nasıl karşılandığını anlama çabası bu makalenin hareket noktasını oluşturmaktadır. Kütahya orta büyüklükte bir Anadolu şehridir. Politik anlamda merkez sağ düşünceye sahiptir. Bu gelişmeler etrafinda yaşanan sürecin, Kütahya'ya nasıl yansıdığını ortaya koymak önemlidir. Makro düzeydeki gelişmelere mikro seviyede nasıl bir siyasal refleks gösterildiğini anlamamıza imkân tanıyacaktır. Bununla birlikte sadece dönemin Türkiye'sindeki yansımaları anlamamıza yardımcı olmakla kalmayacak bugünün Türkiye'sinde sağ siyasal yaşamın düşünsel gelişimini de anlamamıza olanak tanıyacaktır. Bu bağlamda 1960-1971 yılları arasında gerçekleştirilen üç genel seçim sonucu çalışmanın merkezine alınacaktır. Tarihsel olayların Kütahya özelindeki seyri ve istatistiksel verilerden hareketle milletvekili profillerinin yaslandığı sosyolojik tabanı anlama çabası makalenin başlıca amacını oluşturmaktadır.

Anahtar Kelimeler: Milletvekili Genel Seçimleri, Kütahya'da Seçimler, Milletvekilleri Profilleri

\section{THE REFLECTIONS OF DEPUTY GENERAL ELECTIONS ON KUTAHYA: 1960-1971}

\begin{abstract}
Between 1960-1971 coincides the period which ideologies take shape and increase of distinctions/differences between political parties in Turkey. Politicization seems at the highest level in this period, which started with the military intervention on May 27 and ended with the Memorandum of March 12. The repercussion of student movements on 1968 to Turkey is also among the prominent titles. The starting point of this article is the effort to understand how macro developments in both the world and the country's agenda are reflected at the micro level. Kutahya is a medium sized Anatolian city. Politically, it has center-right spectrum. It is important to reveal how the process encountered around these developments reflected on Kutahya. It will allow us to understand what kind of a political reflex is shown to macro level developments at the micro level. In addition to this, it will not only help us understand the reflections in Turkey of that period, it will allow us to understand the intellectual development of right political life in today's Turkey. In this context, the results of the three general elections held between 1960-1971 will be in the focus of the study. The main purpose of the article is to try to understand the sociological base of deputies from the course of historical events in Kutahya and statistical data.
\end{abstract}

Keywords: Deputy General Elections, Elections in Kutahya, the profiles of deputies

1 Dr. Öğr. Üyesi, Kütahya Dumlupınar Üniversitesi, Fen-Edebiyat Fakültesi, Sosyoloji Bölümü, gokhan.gokturk@dpu.edu.tr, ORCID: 0000-0003-2375-6823.

Başvuru Tarihi (Received): 04.05.2021 Kabul Tarihi (Accepted): 29.07.2021 


\section{Giriş}

Türkiye'de siyasal hayatın şekillenmesinde çok partili sisteme geçilmesinin önemli bir rolü bulunmaktadır. Bu süreç sancılarıyla, tartışmalarıyla birlikte demokrasinin önemli kazanımları altında 27 Mayıs askeri müdahalesine kadar devam etmiştir. Ancak 27 Mayıs sonrası dönem, önceki siyasal tartışmaların miras alındığ 1 siyasal gelenek ve kadrolar haricinde yeni bir yapılanma da içermektedir. Bu yeni yapılanma öncelikle siyasal partilerin ideolojik olarak netlik kazanmaya başladığı bir evre olarak kabul edilebilir. Bu dönemde Demokrat Parti (DP) ve Cumhuriyet Halk Partisi (CHP) arasındaki ideolojik belirlenim muğlak bir temele yaslanmaktaydı. İdris Küçükömer bu farkı Doğucu-İslamcı ve Batıcı-laik tanımlamayla iki temel hatta keskin ayrımlarla ele alır (Küçükömer, 2007). Ancak bu keskinliğin izlerini 27 Mayıs 1960 öncesinde görmek mümkün değildir. Kemalist modernleşme anlamında Cumhuriyet Halk Partisinin Batılı bir çizgide modernleşme eğilimi sergilemesi söz konusuyken, Demokrat Partinin modernleşme eğilimleri yanında geleneksel/muhafazakâr bir ayrıma dayanma refleksi söz konusudur. Bu ayrım, 'merkez' sol ve 'merkez' sağ partilerini ifade eden, Batı(c1)lı modernleşmeci laik sistem ve Batı(c1)lı geleneksel, liberal, dini sistem üzerine kuruludur. Türkiye merkez sol partilerini temsil eden CHP çizgisi birinci yolda hareket ederken Türkiye merkez sağ partileri ikincisinden hareket etmeyi doğru bulmaktadır (Göktürk, 2012). Ancak belirtildiği üzere bu ayrım belirli eksenlerde bir aradalığa da sahiptir. Burada muğlaklıktan kasıt iktisadi anlamda devletçi ve liberal bir programın/doktrinin uygulanabilirliği noktasında net bir ayrımın koyulamamasıdır. Liberal ve devletçi politikalar/doktrinler iç içe geçmekteyken Batı lehinde siyasal tavır alma ortak bir zemini oluşturmaktadır. Özellikle Halk Partisinin pragmatist bir anlayışla belirlediği programlarındaki geçişkenlik partiler arasındaki ayrımları azaltmakta diğer bir ifadeyle muğlaklaştırmaktadır. Bu anlamda 27 Mayıs sonrası dönem partilerin özellikle CHP'nin 1965 yılı sonrasında “Ortanın Solu” programını benimsemesi ile birlikte daha doktriner bir eğilim kazanmasını ve siyasal alanda gerçek manada ideolojik ayrımlar üzerinden tartışmayı belirginleştirmiştir. Sürecin solda ve sağda yansıması ise birbirinden farklılaşmaktadır. Türkiye solu kendisini daha erken bir biçimde teorik düzlemde tanımlama ihtiyacı hissederken, sağ toplumsal alanda geleneksel kodlar üzerinden erken Cumhuriyet döneminin sancılarının yaslandığı kodlarla ve özellikle DP'nin belirlediği hat üzerinden tedricen konumlandıracaktır. 27 Mayıs sonrasında CHP sürekliliğini devam ettirirken, ihtilal sonrası siyasal alandan çekilmek zorunda kalan DP, arkasında önemli bir siyasal mirasla birlikte örgütlü bir seçmen tabanı da bırakmıştır. 27 Mayıs sonrasında sağ siyasal alanda yer alan partiler arasında önemli bir problem bu mirasın devamlılığını hangi partinin alması gerektiğiydi. Başka bir ifadeyle de Adnan Menderes'in liderliğinin yeni dönemde kimin etrafinda şekilleneceğidir. Bu yönde DP'nin mirasını elde etme çabasında Adalet Partisinin başı çektiği görülmektedir (Abadan, 1966). AP'nin yanında Cumhuriyetçi Köylü Millet Partisi (CKMP) ve Yeni Türkiye Partisi (YTP) de DP seçmeninin oylarını elde etmek için mücadele göstermektedirler. Bu iki parti her ne kadar DP'ye karşı önemli muhalefet göstermiş olsalar da DP'nin oylarını almak için kıyasıya mücadele etmektedirler (Kili, 1976). Bu çaba en açık biçimiyle YTP programlarında görülmektedir. YTP, 27 Mayıs hareketinin DP'li vatandaş kitlelerine karşı değil, liderler kadrosuna yöneltilmiş olduğunu bu yüzden de mevcut ve yeni kurulacak partilerin DP mensuplarına saflarına açmaları gerektiğini ifade etmektedir (Abadan, 1966). CKMP'nin başında 1950 öncesinde DP'den ayrılan Osman Bölükbaşı bulunmaktadır. YTP'nin başında Ekrem Alican ve AP'nin başında ise ordudan emekli edilen Ragıp Gümüşpala yer almaktadır. Bu doğrultuda 27 Mayıs etkileri altında demokratikleşme çabaları, sağda DP'nin koltuğuna oturma yarışı, anayasal düzen tartışmaları altında 1961 seçimleri farklı dinamikler altında gerçekleştirilecektir.

\section{1961 Milletvekili Genel Seçimleri ve Kütahya}

27 Mayıs sonrası süreçte yeniden demokrasi yönünde karşımıza çıkan ilk mücadele 1961 seçimleridir. Seçimlere büyük oranda 27 Mayıs askeri müdahalesi sonucu ile kapatılan DP'nin 
konumu damga vurmuştur. Seçim öncesinde Cumhurbaşkanı Gürsel başkanlığında yuvarlak masa toplantısı tertip edilip milli bir anlaşma imzalanmıştır ("Milli Anlaşma", 1961). Toplantı sonucu Atatürk ilkelerine bağlı kalınması, DP'nin hiçbir parti propagandası ile temsil edilmemesi, komünizm ve ırkçılık faaliyetlerinde bulunulmaması gibi başlıklar tüm partiler tarafından kabul edilmiştir ("Tebliğin Metni", 1961). Seçimlerde partilerin öne sürdüğü temel propagandalar partilerin seyrini belirlemektedir. CHP köylerde ve şehirlerde farklı bir propaganda belirlemiştir. Kırsal alanda ekonomik geçim üzerine daha somut propagandalar dikkat çekerken, şehirlerde kendilerinin tecrübeli olduğuna yönelik vurguların öne çıkarıldığı makro siyaset alanına yönelik kampanya oluşturulmuştur ("Partiler Adaylık", 1961). AP'de ise durum farklıdır. DP'nin devamı olma iddialarına karşı savunma çabaları dikkat çekmektedir. Bu doğrultuda Gümüşpala'nın Kütahya'da yaptığı seçim konuşmasında kardeşlik vurgusunu ön plana çıkarttığı görülmektedir ("Düşmanlık Yok", 1961). Buna karşın parti üyelerinin seçim meydanlarında "demokrat" sözcüğünü kullanmaları sonrası tevkif edilmesi gibi sorunlarla da mücadele etmektedirler ("A.P. li Bir Kadın”, 1961). Ancak Gümüşpala'nın ilk miting yerini Eskişehir olarak seçmesi metaforik bir anlam içerir. Adnan Menderes'in tamamlayamadığı son seçim mitingi olan Eskişehir'den seçim konuşmalarına başlanması kalınan yerden devam vurgusuyla DP kitlelerine önemli bir mesaj içermektedir ("Parti Liderleri" 1961). CKMP ve YTP'de ise durum daha çok kendilerine rakip gördükleri AP'ye yüklenme üzerinden yürütülmektedir. Milli anlaşmaya karşın DP'nin eski kadroları üzerinden örgütlenerek yerelde seçim başarısı yakalama arayışları başlıca çabayı oluşturmaktadır ("Bölükbaşı ve Gümüşpala", 1961). Seçim çalışmaları Yassıada duruşmalarının gölgesinde sürdürüldü. 16 Eylül'de Polatkan ve Zorlu'nun, 17 Eylül 1961'de Menderes'in idam1 yapıld1 (“F.R. Zorlu”, 1961; “Menderes'te", 1961).

Seçimler idamdan bir ay sonra 15 Ekim 1961'de gerçekleştirildi. 1961 seçimleri öncesi ulusal düzeyde yaşanan bu gelişmelerin Kütahya'da da karşılık bulduğu görülmektedir. Bilindiği üzere Adnan Menderes vekillik görevini Kütahya'dan kazanmıştı. 27 Mayıs sonrası Adnan Menderes'e pek çok yerde olduğu gibi Kütahya'da da fahri belediye başkanlığı verilmiştir. 27 Mayıs sonrası ise verilen fahri belediye başkanlığı unvanları birer birer kaldırılmıştır. Bu tartışmalardan biri de Kütahya'da yaşanmıştır. Temsilciler Meclisi üyesi ve Meclis Divan Kâtibi Rifat Çini'nin, 19 Haziran 1961 tarihli oturumda Kütahya'da sabık başbakana verilen unvanın kaldırılmasında nasıl zorluklar yaşadıklarına dair bir soru önergesi verdiği görülmektedir (TBMM.Z.C., 1961). Dolayısıyla kapatılan DP ile bağlantılar, süreklilikler seçim gündeminin başlıca konusunu oluşturmaktadır. 1961 seçimleri öncesinde Kütahya'da toplam nüfus 384.915 olup seçmen sayıs1 187.082'dir. 1950 ve 1960 arasında yapılan üç seçim çoğunluk seçim usulü ile gerçekleştirilmiş olup Demokrat Parti hepsini önde tamamlamıştır (Sevik, 1961). Bunun yanı sıra Temmuz 1961'de yapılan Anayasa halk oylamasında Kütahya yeni anayasaya kırmızı pusula ile hayır veren illerin başında gelmektedir. Oylama16.770 kabul oyuna karşılık 25.218 hayır oyuyla sonuçlanmıştır ("Netice", 1961). 1960 seçimleri öncesi DP döneminde ile yapılan yatırımlar, siyasal tercihlerdeki uyumların örtüşmesi gibi çeşitli nedenlerden ötürü Demokratların kalesi konumundaydı. Anayasaya hayır verilmesi bu anlamda şaşırtıcı değildir. Her ne kadar açıktan konuşulması mümkün olmasa da Kütahya'da seçimler öncesi 1946-1960 Demokratlarından oluşan blok bir kitle bulunmaktadır. Bu kitle kendisine yeni bir parti aramaktadır. AP, CKMP ve YTP başlıca adaylardır. Ancak henüz teşkilatını tamamlayamamış YTP'nin AP ve CMKP karşısında Kütahya'da bir şansı bulunmamaktaydı. Demokratlar, AP ve CKMP arasında gidip gelmekteydi. CHP il sözcüsü Tevfik Alpaslan Demokratlar ile ilgili sessiz kalmayı tercih ettiklerini belirtmekte iken AP il başkanı Dr. Osman Özbilen Adnan Menderes zamanında açılan şeker fabrikası, azot fabrikası, kömür işletmelerine vurgu yaparak ekonomik devamlılık için adresin AP olduğunu belirtmektedir (Sevik, 1961). Seçim öncesinde adaylar şu isimlerden oluşmaktadır: CHP Senatör: Osman Ertokuş, Süleyman Gündüz Günyüz. CKMP Senatör: H. Baha Özbek, H. Cevdet Erkul. AP Senatör: Ethem Erdinç, Osman Özbilen. YTP: Senatör adayı yok. Milletvekili adayları ise şu isimlerden oluşmaktadır. CHP adaylart: Ahmet Bozbay, Ali Erbek, Lütfi Güran, Necip Alaiyeli, 
Şakir Coşkun; CKMP adayları: Sadrettin Tosbi, Mehmet Kesen, Hakkı Azmanoğlu, Azmi Eren, Ahmet Ener, Selim Erdil; AP adaylart: Rauf Kural, Sezai Sarpaşar, Şerafettin Coşer, İhsan Şahinalp, A. Sadi Öncel, M. Sabit Sağdıç; YTP adayları: Ahmet Kavuncu, Kazım Kasımoğlu, İsmail Özütemiz, Halil Korkmaz, Emin Saban, Rifat Sander (“İlimizdeki Siyasi”, 1961). Adaylardaki en dikkat çeken özellik AP adaylarında görülmektedir. AP adayları incelendiğinde DP ile olan süreklilikler göze çarpmaktadır. Senatör adayları eski DP milletvekilliği görevinde bulunmuş olup milletvekili adayı Sezai Sarpaşar DP'den eski belediye başkanlığ görevinde bulunmuştur. Aynı şekilde CKMP adayları Ahmet Ener (Emet), Mehmet Kesen (Merkez) DP döneminde belediye başkanlığı görevinde bulunmuştur (kutahya.bel.tr, 2021). Adayların çoğunluğu Kütahya doğumlu olup merkezden gösterilen az sayıda aday bulunmaktadır. Partilerdeki adaylar hâkim, avukat, doktor, çiftçi, tüccar, veteriner gibi üniversite mezunu beyaz yakalı mesleki sınıflar ile diğer taraftan ticaret/tüccara yaslanan eşrafa dayanmaktadır. Özellikle seçimleri kazanacak olan milletvekili ve senatörler ise aktif siyasetten gelmekte olup Mehmet Kesen, Ahmet Bozbay ve Sezai Sarpaşar gibi isimler belediye başkanlığı görevlerinde de bulunmuşlardır. Adaylar işlevselci yaklaşım açısından şehrin önde gelen kanaat önderlerine dayanmaktadır denilebileceği gibi elitist kuram açısından seçkinci bir görünüme de sahiptir. $\mathrm{Bu}$ gelişmeler ve görünümler altında seçimler 15 Ekim 1961 tarihinde gerçekleştirilmiştir. 185 bin seçmenden 145 bini sandığa giderek \%81 oranında seçimlere katılım göstermiştir. Senatör seçiminde AP 49.746 oy, CHP 39.937 oy ve CKMP 51.757 oy almış bulunmaktadırlar. Bu netice ile Kütahya'ya ait iki senatörlük görevini CKMP adayları Bahattin Özbek (veteriner) ve Erkut Osman Cevdet (asker, hukuk) kazanmış oldular (“Senatörlüğü", 1961; “İlimizin”, 1961). Milletvekili seçimlerini ise üç parti eşit milletvekili çıkartarak ikişer vekillik ile paylaşmıştır.

Tablo 1: 1961 Milletvekili Genel Seçimi Kütahya İli Sonuçları

\begin{tabular}{|c|c|c|c|c|}
\hline \multicolumn{5}{|c|}{1961 Milletvekili Genel Seçimi Kütahya İli Sonuçları } \\
\hline Seçim Çevresi & $\mathbf{A P}$ & CHP & CKMP & YTP \\
\hline $\begin{array}{c}\text { Kütahya } \\
\text { Milletvekili/Senatör }\end{array}$ & $\begin{array}{c}50.156 \\
49746 \\
34,2 \\
2 \mathrm{Mv} .\end{array}$ & $\begin{array}{c}40.177 \\
39937 \\
27,4 \\
2 \mathrm{Mv} .\end{array}$ & $\begin{array}{c}53.155 \\
51757 \\
36,2 \\
2 \mathrm{Mv} .\end{array}$ & $\begin{array}{l}3.237 \\
4314 \\
2,2 \\
-\end{array}$ \\
\hline Altuntaş & $\begin{array}{l}1.952 \\
1837 \\
16,3\end{array}$ & $\begin{array}{l}3.400 \\
3231 \\
28,3\end{array}$ & $\begin{array}{c}6.295 \\
6335 \\
52,4\end{array}$ & $\begin{array}{l}365 \\
365 \\
3,0\end{array}$ \\
\hline Domaniç & $\begin{array}{c}3.998 \\
4014 \\
62,6\end{array}$ & $\begin{array}{l}1.799 \\
1806 \\
28,2\end{array}$ & $\begin{array}{c}468 \\
463 \\
7,3\end{array}$ & $\begin{array}{l}121 \\
121 \\
1,9\end{array}$ \\
\hline Emet & $\begin{array}{l}4.878 \\
4597 \\
24,9\end{array}$ & $\begin{array}{l}5.497 \\
5861 \\
28,1\end{array}$ & $\begin{array}{l}8.907 \\
8578 \\
45,5\end{array}$ & $\begin{array}{l}418 \\
372 \\
2,1\end{array}$ \\
\hline Gediz & $\begin{array}{c}4.174 \\
4129 \\
18,3\end{array}$ & $\begin{array}{l}7.037 \\
6493 \\
30,8\end{array}$ & $\begin{array}{c}11.314 \\
10417 \\
49,5\end{array}$ & $\begin{array}{c}338 \\
338 \\
1,5\end{array}$ \\
\hline Merkez & $\begin{array}{c}9.350 \\
9276 \\
24,1\end{array}$ & $\begin{array}{c}10.102 \\
10205 \\
26,0\end{array}$ & $\begin{array}{c}18.345 \\
18259 \\
47,3\end{array}$ & $\begin{array}{c}888 \\
888 \\
2,3\end{array}$ \\
\hline Simav & $\begin{array}{c}13.399 \\
56,4\end{array}$ & $\begin{array}{l}6.506 \\
6374 \\
27,4\end{array}$ & $\begin{array}{c}3.494 \\
3439 \\
14,7\end{array}$ & $\begin{array}{c}372 \\
372 \\
1,6\end{array}$ \\
\hline Tavşanlı & $\begin{array}{c}12.415 \\
12521 \\
53,2\end{array}$ & $\begin{array}{l}5.836 \\
5965 \\
25,0\end{array}$ & $\begin{array}{c}4.332 \\
4266 \\
18,6\end{array}$ & $\begin{array}{r}735 \\
735 \\
3,2\end{array}$ \\
\hline
\end{tabular}


Seçim neticesinde Kütahya'da tek kaybeden Kütahya'da örgütlenmesini tamamlayamadan seçime girmek zorunda kalan YTP oldu. YTP teşkilatlarını Doğu Anadolu bölgesi yerine öncelikle nüfus hareketliliği yoğun olan Ege bölgesinde kursaydı sonuçlar farklı olabilirdi (Abadan, 1966). AP ile CKMP yakın oy alarak ilk iki sırayı paylaştı. CHP ise üçüncü parti oldu. Buna karşılık nispi temsil sistemi gereği her üç partide ikişer milletvekili kazandı. Demokrat Partili eski isimleri ve tabanını barındıran iki parti 1961 seçim sonuçları itibariyle Kütahya'da DP'nin vekaletini almış görünmemektedir. Aralarında sadece 3 bin oy farkı bulunmaktadır. CKMP yedi seçim bölgesinin dördünü önde tamamlamıştır. Bunlar Merkez, Altıntaş, Emet, Gediz ilçeleridir. AP ise Domaniç, Simav ve Tavşanlı'da seçimi önde tamamlamıştır. CHP ise tüm seçim bölgelerinde ikinci parti olmuştur. Demokrat oylarının ya AP'ye ya da CKMP'sine gittiği anlaşılmaktadır. Sağ ve sol partiler arasında bir genelleme yapmak gerekirse \%25'lik sol seçmen tabanına karşın \%70'lik oranla sağ düşünceye sahip seçmen profilini görülmektedir.

Tablo 2: 1961 Kütahya Milletvekili Yaş Kategorileri

\begin{tabular}{ccccc}
\hline Yaş Kategorileri & AP & CHP & CKMP & Genel Oran \\
\hline \multirow{2}{*}{$\mathbf{3 9}$ ve Alt } & 1 & - & - & 1 \\
& 50,0 & - & - & 16,7 \\
$\mathbf{4 0 - 4 9}$ & - & 1 & 2 & 3 \\
& - & 100,0 & 100,0 & 49,9 \\
$\mathbf{5 0 - 5 9}$ & 1 & - & - & 1 \\
& 50,0 & - & - & 16,7 \\
$\mathbf{6 0}$ ve Üstï & - & 1 & - & 16,7 \\
& - & 100,0 & - & 6 \\
Toplam & 2 & 2 & 2 & 100,0 \\
Yaş Ortalaması & 100,0 & 100,0 & 100,0 & 47,3 \\
\hline
\end{tabular}

Kütahya'dan seçilen 6 milletvekilinin yaş durumu incelendiğinde siyasetin erken dönem seyrettiği sınıflamalara göre genç bir profil ortaya çıkmaktadır. AP'den Sezai Sarpaşar 32 yaş ile en genç milletvekili iken CHP'li Ahmet Boz 60 yaş ile ilin en yaşlı milletvekilidir. Parlamentoda şehri temsil etme bağlamında genç/dinamik bir vekil profili olacağı belirtilebilir. Bu seçim dönemi CHP'li Ahmet Bozbay'ın ikinci dönem milletvekilliğidir. Diğer 5 vekil ilk kez parlamento tecrübesi yaşayacaktır. Parlamento tecrübesinden ziyade partilerin parlamento dışı yeni isimlere yöneldiği belirtmek gerekir. Kütahya milletvekilleri yaş ortalaması 1950 seçimlerinde Kütahya'da 49, 1954 seçimlerinde 46, 1957 seçimlerinde ise 40 idi (Göktürk, 2013). 1961 seçimi sonrası ise bu oranın 47 olduğu görülmektedir. Milletvekillerinin yaş alanındaki ortak özelliklerinde şu unsurlar göze çarpmaktadır; vekillerin tamamı otuzlu yaşlarını CHP hükümetleri altında geçirmiş olduğu ve hemen hemen hepsinin eğitim yılları ve ideolojik şekillenmelerinin tek parti dönemine denk geldiği görülmektedir. $\mathrm{Bu}$ anlamda Cumhuriyete geçiş ve çok partili dönem sancıları milletvekillerinin başlıca siyasal tecrübelerini oluşturmaktadır.

Tablo 3: 1961 Kütahya Milletvekili Yerellik

\begin{tabular}{ccccc}
\hline Yerellik & AP & CHP & CKMP & Genel Oran \\
\hline \multirow{2}{*}{ Ayn $\iota$} & 1 & 2 & 1 & 4 \\
& 50,0 & 100,0 & 50,0 & 66,37 \\
Farkl & 1 & - & 1 & 2 \\
& 50,0 & - & 50,0 & 33,3 \\
\multirow{2}{*}{ Toplam } & 2 & 2 & 2 & 6 \\
& 100,0 & 100,0 & 100,0 & 100,0 \\
\hline
\end{tabular}

Yerellik durumuna bakıldığında CHP'li iki vekil Kütahya doğumludur. AP'nde ve CKMP'nde ise birer milletvekili şehir dışından kazanmıştır. Ayrıca senatörler de incelendiğinde bir senatörün 
Kütahya'dan diğer senatörün ise Kütahya dışından olduğu görülmektedir. 1946 seçimlerine kadar CHP'nin mahalli teşkilatının bile fikrini almadan parti merkezi tarafından tayin edilen milletvekilleri için seçim bölgeleri yabancı hatta belki de ilk defa gördükleri bir yerdi (Ayata, 1990). Bu sebeple milletvekillerinin seçilme bölgesine göre kendi memleketinden aday gösterilme durumu özellikle seçmenler açısından önem arz etmektedir. Seçmen, yerelliğe sahip vekilin şehrin sorunlarına daha hâkim olduğuna inanmaktadır. Bu anlamda Kütahya'da da seçim öncesinde partiler bütün milletvekili ve senatörlerin Kütahyalı olmasını istediklerini halkın beklentisinin de bu yönde olduğunu belirten açıklamalara sahiptirler (“Kimler Seçildi”, 1961). Türk toplum yapısı içinde hemşerilik anlayışının yaygın olması kentleşmenin geleneksel kodlar üzerine inşa edilmesi de yerellik tavrının belirleyicileri arasındadır.

Tablo 4: 1961 Kütahya Milletvekili Ĕ̈itim

\begin{tabular}{ccccc}
\hline Eğitim Seviyesi & AP & CHP & CKMP & Genel Oran \\
\hline İlkokul & - & - & 1 & 1 \\
& - & - & 50,0 & 16,7 \\
Ortaokul, Rüsstiye & - & 2 & - & 2 \\
& - & 100,0 & - & 33,3 \\
Lise, Idadi, Sultani, Kolej, Meslek Okulu & 1 & - & - & 1 \\
Unniversite & 50,0 & - & - & 16,7 \\
& - & - & 1 & 1 \\
Askeri Okullar & - & - & 50,0 & 16,7 \\
& 1 & - & - & 1 \\
Toplam & 50,0 & - & - & 16,7 \\
& 2 & 2 & 2 & 6 \\
& 100,0 & 100,0 & 100,0 & 100,0 \\
\hline
\end{tabular}

Türkiye'nin modern tarihi boyunca başlıca sosyal ayrım eğitim kanalıyla meydana gelmektedir. Başlangıçta askeri okullar ile başlayan eğitim-modernleşme ilişkisi, 19. yüzyılın ikinci yarısında Mülkiye (1859), Hukuk Fakültesi (1888) ve Amerikan destekli Robert Koleji (1860) gibi seküler eğitim kurumlarıyla sivil alana da yayıldı. Cumhuriyet sonrasında Atatürk devrimleri ile birlikte açılan yüksek öğretim kurumları ile bu yapı güçlendirildi (Frey, 1965). Milletvekilleri profilinde de eğitim önemli bir değişken durumundadır. Toplumsal yapının o günkü gelişme seyri ile toplumsal sınıflar arasında kuvvetli bir bağ bulunmaktadır. Erken Cumhuriyet döneminde Türk modernleşmesinin temel taşıyıcısı olan askeri elit sınıf Cumhuriyetin ilerleyen aşamalarında bu yoğunluğu kaybetmiştir. Öte yandan sivil aydınlar arasında doktor ve hukukçu kimliği parlamentoda en çok temsil bulan mesleki grubu oluşturmaktadır (Frey, 1965). 1961 seçimleri sonucunda parlamentoda Kütahya özelinde milletvekillerinin eğitiminde öne çıkan eğilim ülke genelinin aksi yönündedir. Bu sonuçlar 1946-1960 yılları arasında mevcut olan Kütahya ortalamasına da ters düşmektedir. Belirtilen dönem arasında üniversite mezunları çoğunluktadır (Göktürk, 2012). Önceki seçimlerde bir parti çoğunluğu aldığ için parti içi aday listesi çeşitlenebilmekteydi. Ancak 1961 seçimlerinde her parti ikişer vekil kazandığı için liste başı olan ve tanınmış olan adaylar önceliği almıştır. Bu dönem itibariyle bir üniversite mezunu bulunmaktadır. O da şehir dışından gösterilen milletvekiline aittir. Askeri okul mezunu bir vekil bulunmaktadır. Ağırlık ilk ve orta derece tahsilidir. 
Tablo 5: 1961 Kütahya Milletvekili Meslek

\begin{tabular}{ccccc}
\hline Meslek* & AP & CHP & CKMP & Genel Oran \\
\hline Asker & 1 & - & - & 1 \\
& 33,3 & 1 & - & 7,7 \\
Maliye & - & 25,0 & 1 & 7,7 \\
Ticaret & 1 & 1 & 1 & 3 \\
& 33,3 & 1 & 20,0 & 23,0 \\
Tüccar & 1 & 25,0 & 20,0 & 3 \\
& 33,3 & 1 & & 23,0 \\
Çiftçi & - & 25,0 & 1 & 1 \\
Akademisyen & - & - & - & 1 \\
& & 1 & 20,0 & 7,7 \\
Ziraat & - & 25,0 & 40,0 & 1 \\
Belediyecilik & - & & & 2 \\
& & & & 15,3 \\
\hline
\end{tabular}

*Mesleklerdeki rakamlar birer kişiyi temsil etmemektedir. Bir milletvekili birden fazla mesleki statüye sahiptir. Oranlar buna bağll olarak değerlendirilmektedir.

Eğitim koşullarının yanı sıra mesleki formasyon da milletvekili profilinin önemli belirleyici unsurudur. Milletvekillerinin birden fazla uğraşısı olduğu için meslekleri tekil tanımlayamamaktayız. 1961 seçim sonuçları itibariyle Kütahya'da vekillerin önce çıkan özelliği ticaret/tüccar temelli eşrafa dayalı olmasıdır. Ayrıca ziraat/çiftçi kodlamasının iç içe olduğu göz önünde bulundurulduğunda ticaret/tüccar/ziraat/çiftçi kategorileri Anadolu'da eşrafı simgeleyen mesleki formasyon grubunu oluşturmaktadır. İkinci derecede öne çıkan özellik belediyeci olmanın vekil olmak için bir öncelik kazandırdığıdır. Siyasi tecrübe ve belediyeciliğin sağladığı çevresel tanınırlık meclise giden yolda önemli bir ayrım yaratmaktadır. Asker ve akademisyen vekiller ise merkezden gösterilen vekillere aittir.

\section{1965 Milletvekili Genel Seçimleri ve Kütahya}

1965 seçimleri ideolojik söylemlerin arttı̆̆ iktidarın sivil ellere devrinden sonra ortaya çıkan şiddetli görüş ayrılıkları ve silahlı isyan/darbe teşebbüsleri tek bir partinin istikrarlı siyasi ortamı sağlamasına izin vermemiştir. Nispi temsil sisteminin ilk defa uygulanması hiçbir partiye mutlak çoğunluğu vermemiş ve son dört yıl içinde dört koalisyon hükümeti ile idare edilmiştir (Abadan, 1966). Toprak reformu, petrol meselesi ve ekonomide kalkınma tartışmaları 1960 sonrası temel tartışma konuları arasındadır. 1929 Dünya Büyük Buhranı sonrası başlayan Keynesyen Refah Devleti kalkınma modeli liberal politikalar yerine Batı'da yaygınlık kazanmaya başlamıştır. Devlet Planlama Teşkilatının kurulması Türkiye'nin kalkınmada kurumsallaşma çabalarını ortaya koymaktadır. Ancak CHP'nin 1965 sonrası ortanın solu tartışmalarını gündeme getirmesi, ABD ve Sovyetler arasındaki soğuk savaş dönemi kalkınma tartışması basit bir yöntem tartışmasını aşmaktadır. Kalkınmada devletçi yaklaşımların sosyalizm ile eşdeğer tutulduğu bir siyasi ortamda mesele bir rejim problemine dönüşmektedir. Solda madenlerin, petrollerin devletleştirilmesi tartışması ile sağda özel sektör gelişimine ait liberal tartışmalar öne çıkmaktadır. Ayrıca sol aydınların oluşturduğu dergi ve siyasi dernek faaliyetleri hızlanmıştır. Yön Dergisi, Sosyalist Kültür Derneği solda dikkat çeken oluşumlardır. Sağda ise Komünizmle Mücadele Dernekleri öne çıkmaktadır. Dış politikada ise Kıbrıs meselesi, Kuzey Atlantik Antlaşması Örgütü (NATO) ve Merkezi Antlaşma Teşkilatı (CENTO) antlaşmaları genel siyasi manzarayı oluşturmaktadır (Abadan, 1966).

Seçimler bu ana başlıklar altında 10 Ekim 1965 tarihinde gerçekleştirilmiştir. Seçimlere AP, CHP, YTP, CKMP'nin yanı sıra CKMP'den ayrılan MP ve sosyalist bir parti olan Türkiye İşçi Partisi (TIP) de katıldı. TIP'in seçimlere katılmasıyla ortanın solunda duracağını belirten CHP'ye daha 
solda bir rakip gelmiş oldu. AP bu seçimlere lider değişikliği ile gitti. Süleyman Demirel 1964 yılında Genel Başkanlığa seçildi (“Demirel AP”, 1964: 1). CKMP'de de liderlik değişti. Alparslan Türkeş, Ahmet Tahtakılıç ile girdiği kongre yarışını kazanarak CKMP genel başkanı seçildi ("Türkeş başkan" 1964). Bir önceki seçimde CKMP Genel Başkanı olan Osman Bölükbaşı ise Millet Partisi Genel Başkanı sıfatı ile seçimlere katıldı. Seçimlerdeki önemli bir değişiklik de seçim sisteminde meydana geldi. Özellikle AP milletvekillerinin karşı çıkışına rağmen diğer partiler tarafından milli bakiye usulü mecliste müzakere edilerek kabul edildi (TBMM.Z.C., 1965). Milli bakiye usulü seçime giren küçük partilere de mecliste temsil imkânı tanıdı.

AP seçimler öncesinde parti ambleminde değişikliğe gitti. Parti amblemini güneş ve kitaptan beyaz "Kırat"a çevirdi. Bu diğer partiler tarafından tartışma konusu haline getirldi. CHP sözcüsü Suphi Baykam demir "Kırat"'n demokrat çağrışımı yaptığı ve AP'nin DP'nin devamı olduğunun ispatı olduğunu belirtti (AP'nin sembolü, 1965). 1965 seçimlerinde de DP ve Adnan Menderes'in seçimlere damga vurmaya devam ettiği görülmektedir. Seçimlere Kütahya'da 5 parti ve bir bağımsız aday katılmıştır. CKMP ve MP'nin bölünmesi her yerde olduğu gibi Kütahya'da da AP'nin işine yaramıştır. 1961 seçimlerinde 50 bin oy alan AP 1963 mahalli seçimlerinde 79 bin oy, 1964 kısmi senato seçimlerinde ise 74 bin oy almıştır. CHP'nin 1963 seçimlerindeki 49 bin oyu ise kısmi senato seçimlerinde 34 bine düşmüştür. Seçim öncesinde Kütahya'daki beklentiler AP'nin 3, CHP'nin 2 ve milli bakiyeye ise 1 vekil düşeceği yönündedir. Kütahya'da zayıf olan YTP'nin şansı bulunmamakla birlikte milli bakiyeden CKMP veya MP yararlanacaktır (Nebioğlu, 1965).

Seçim propagandalarında partiler köylere ağırlık verdiler. Köyden merkeze seçim propagandası ile hareket eden partiler, kazalarda özellikle kampanyalarını pazarların kuruldukları günlere getirmek suretiyle kalabalık toplulukları etkilemeye çalışmaktadırlar ("Şehrimiz Siyasi", 1965). CHP eskiden beri gelen kemikleşmiş oylarına güvenmektedir (“C.H.P.'liler Donmuş”, 1965). Kütahya'da örgütlenmesine geç kalan YTP'de ise diğer partilerin saflarından üye toplama çalışmaları ön plana çıkmaktadır. Ayrıca adayları olan Emin Yücel'i milli bakiye adayı olarak merkezden koyduğu için muhtemelen bir milletvekili kazanmasına kesin gözüyle bakılmaktadır ("Y.T.P. her" 1965). Millet Partisi ise il örgütünde yaşanan anlaşmazlıklar dolayısıyla ön seçim yapmadan genel merkezin gösterdiği adaylar ile eski DP'li isimler başta olmak üzere seçime hazırlanmaktaydı ("Millet partisi", 1965). AP ise özellikle kalabalık ilçelerden gösterdiği kanaat önderlerine güvenmekte olup açık hava mitingleri ve köy ziyaretleri ile dört milletvekili kazanma hedefindedirler (“A.P. açık”, 1965). CKMP ise aynı şekilde köylerde ve kasabalarda broşürler ile propaganda yapıp Alpaslan Türkeş' in konuşmalarıyla takviye etmeye çalışmaktadırlar ("C.K.M.P. Köy”, 1965). Kütahya'nın temel sorunlarında ise Seyitömer Termik Santralinin kurulmas1, Azot fabrikalarının genişletilmesi ve Şap fabrikasının kurulması kalkınma çabalarında ildeki önemli iktisadi meseleleri oluşturmaktadır ("Seyitömer termik", 1965). Seçimlere parti liderlerinden hiçbiri Kütahya'ya gelme firsatı bulamamıştır ("Seçim kampanyasına”, 1965). Bu gelişmeler altında 10 Ekim 1965 tarihinde seçimlere gidilmiştir. Seçim sonuçlarına göre Türkiye çapında AP birinci parti oldu. Kütahya' da da AP dört milletvekilliği ile birinci, CHP bir milletvekili, MP de bir milletvekili çıkarma başarısı gösterdi (“Kütahya'da AP”, 1965). YTP'nin milli bakiye beklentisi ile CHP'nin beklentileri boşa çıkmış oldu. 
Tablo 6: 1965 Milletvekili Genel Seçimi Kütahya İli Sonuçları

\begin{tabular}{|c|c|c|c|c|c|c|c|}
\hline \multicolumn{8}{|c|}{1965 Milletvekili Genel Seçimi Kütahya İli Sonuçları } \\
\hline $\begin{array}{c}\text { Seçim Çevresi } \\
\text { Ve İlçe }\end{array}$ & $\mathbf{A P}$ & CHP & CKMP & MP & TíP & YTP & Bağımsız \\
\hline Kütahya & $\begin{array}{c}81.850 \\
63,7 \\
4 \mathrm{Mv} .\end{array}$ & $\begin{array}{c}35.059 \\
19,5 \\
1 \mathrm{Mv} .\end{array}$ & $\begin{array}{c}4.059 \\
3,2 \\
-\end{array}$ & $\begin{array}{c}14.187 \\
11,0 \\
1 \mathrm{Mv} .\end{array}$ & - & $\begin{array}{c}3.019 \\
2,3 \\
-\end{array}$ & $\begin{array}{c}359 \\
0,3 \\
-\end{array}$ \\
\hline Altıntaş & $\begin{array}{c}4.574 \\
43,4\end{array}$ & $\begin{array}{c}2.456 \\
23,3\end{array}$ & $\begin{array}{c}552 \\
5,2\end{array}$ & $\begin{array}{c}2.400 \\
22,7\end{array}$ & - & $\begin{array}{c}543 \\
5,1\end{array}$ & $\begin{array}{l}26 \\
0,2\end{array}$ \\
\hline Domaniç & $\begin{array}{c}3.958 \\
67,9\end{array}$ & $\begin{array}{l}1.236 \\
21,2\end{array}$ & $\begin{array}{l}125 \\
2,1\end{array}$ & $\begin{array}{l}370 \\
6,4\end{array}$ & - & $\begin{array}{l}122 \\
2,1\end{array}$ & $\begin{array}{l}15 \\
0,3\end{array}$ \\
\hline Emet & $\begin{array}{c}8.497 \\
56,6\end{array}$ & $\begin{array}{c}2.455 \\
16,3\end{array}$ & $\begin{array}{l}747 \\
5,0\end{array}$ & $\begin{array}{c}3.020 \\
20,1\end{array}$ & - & $\begin{array}{r}267 \\
1,8\end{array}$ & $\begin{array}{r}38 \\
0,3\end{array}$ \\
\hline Gediz & $\begin{array}{c}12.971 \\
65,6\end{array}$ & $\begin{array}{c}3.988 \\
20,2\end{array}$ & $\begin{array}{l}527 \\
2,7\end{array}$ & $\begin{array}{c}1.642 \\
8,3\end{array}$ & - & $\begin{array}{c}508 \\
2,6\end{array}$ & $\begin{array}{l}135 \\
0,7\end{array}$ \\
\hline Merkez & $\begin{array}{c}24.525 \\
66,0\end{array}$ & $\begin{array}{c}7.017 \\
18,9\end{array}$ & $\begin{array}{c}1.038 \\
2,8\end{array}$ & $\begin{array}{c}3.649 \\
9,8\end{array}$ & - & $\begin{array}{c}843 \\
2,3\end{array}$ & $\begin{array}{r}75 \\
0,2\end{array}$ \\
\hline Simav & $\begin{array}{c}12.514 \\
67,7\end{array}$ & $\begin{array}{c}3.266 \\
17,7\end{array}$ & $\begin{array}{l}515 \\
2,8\end{array}$ & $\begin{array}{c}1.689 \\
9,1\end{array}$ & - & $\begin{array}{c}474 \\
2,6\end{array}$ & $\begin{array}{l}21 \\
0,1\end{array}$ \\
\hline Tavşanlt & $\begin{array}{c}14.811 \\
68,1\end{array}$ & $\begin{array}{c}4.641 \\
21,4\end{array}$ & $\begin{array}{l}555 \\
2,6\end{array}$ & $\begin{array}{c}1.417 \\
6,5\end{array}$ & - & $\begin{array}{c}262 \\
1,2\end{array}$ & $\begin{array}{l}49 \\
0,2\end{array}$ \\
\hline
\end{tabular}

1965 seçimlerinin Kütahya'da galibi ülke genelinde olduğu gibi AP oldu. AP biri milli bakiye sisteminden olmak üzere 4 milletvekili kazandı. Bir önceki seçimde DP oyları AP ve CKMP arasında ekseriyetle bölüşülmüştü. Ancak 1965 seçimlerinde DP'nin mirasının AP'ye geçtiği anlaşılmış oldu. Bu sonuçlarla AP sadece bir seçim kazanma değil aynı zamanda sağda merkez partisi olma başarısı da göstermiş oldu. Kütahya genelinde $\% 63,7$ ile büyük bir fark oluştu. Ayrıca yedi seçim bölgesinde de AP birinci oldu. 1961 seçimlerinde CHP tüm bölgelerde ikinci partiydi. Bu seçimlerde Emet ilçesi hariç altı bölgede ikinci parti olma özelliğini korudu. Ancak \%63,7'ye karş1lık \% 19,5 gibi bir fark oluşmuş oldu. Bu oran DP dönemi ile benzerlik göstermektedir. CKMP bölünmenin ve yeniden yapılanmanın sıkıntıları açısından en büyük yenilgiyi alan parti konumundadır. Oyları \%36,2'den \%3,2'ye düşmüştür. Ancak MP Bölükbaşı liderliğinde sağ merkezdeki ana partilerden biri olma özelliğini devam ettirmektedir. YTP ise merkez adayına karşın düşük oy alarak herhangi bir başarı gösterememiştir.

Tablo 7:1965 Kütahya Milletvekili Yaş Kategorileri

\begin{tabular}{|c|c|c|c|c|}
\hline Yaş Kategorileri & $\mathbf{A P}$ & CHP & MP & Genel Oran \\
\hline 39 ve Altu & $\begin{array}{c}3 \\
75,0\end{array}$ & $\begin{array}{l} \\
-\end{array}$ & - & $\begin{array}{c}3 \\
50,0\end{array}$ \\
\hline $40-49$ & $\begin{array}{c}1 \\
25,0\end{array}$ & $\begin{array}{c}1 \\
100,0\end{array}$ & $\begin{array}{c}1 \\
100,0\end{array}$ & $\begin{array}{c}3 \\
50,0\end{array}$ \\
\hline $50-59$ & - & - & - & - \\
\hline 60 ve Üstï & - & - & - & - \\
\hline Toplam & $\begin{array}{c}4 \\
100,0\end{array}$ & $\begin{array}{c}1 \\
100,0\end{array}$ & $\begin{array}{c}1 \\
100,0\end{array}$ & $\begin{array}{c}6 \\
100,0\end{array}$ \\
\hline Yaş ortalaması & 36,25 & 42,00 & 48,00 & 39,17 \\
\hline
\end{tabular}

Kütahya özelinde genç bir vekil heyetiyle temsile devam edildiği görülmektedir. Bir önceki seçimlere göre oldukça genç bir milletvekili profili oluşmuştur. Özellikle 39 yaş altı ile AP bu 
ortalamanın oluşmasında etkilidir. Parlamentoda Kütahya genç bir grup ile temsil edilecektir. Ancak seçilen milletvekilleri ilk defa mecliste yer alacaklardır. Dolayısıyla kadrolar yenilenmiştir. $\mathrm{Bu}$ sebeple de genç fakat meclis tecrübesi olmayan bir grup ile Kütahya XIII. dönemde temsil edilecektir.

Tablo 8: 1965 Kütahya Milletvekili Yerellik

\begin{tabular}{|c|c|c|c|c|}
\hline Yerellik & $\mathbf{A P}$ & CHP & MP & Genel Oran \\
\hline Aynı & $\begin{array}{c}3 \\
75,0\end{array}$ & $\begin{array}{c}1 \\
100,0\end{array}$ & - & $\begin{array}{c}4 \\
66,37\end{array}$ \\
\hline Farklı & $\begin{array}{c}1 \\
25,0\end{array}$ & - & $\begin{array}{c}1 \\
100,0\end{array}$ & $\begin{array}{c}2 \\
33,3\end{array}$ \\
\hline Toplam & $\begin{array}{c}4 \\
100,0\end{array}$ & $\begin{array}{c}1 \\
100,0\end{array}$ & $\begin{array}{c}1 \\
100,0\end{array}$ & $\begin{array}{c}6 \\
100,0\end{array}$ \\
\hline
\end{tabular}

Milli bakiye seçim sistemine geçilmiş olmasından dolayı pek çok ilde oluğu gibi Kütahya'da da partiler yerel adaylara yer verme eğilimi gösterdiler. İlk olarak AP ve CHP Kütahya' da merkezden aday göstermeme kararı aldılar (“A.P. ve C.H.P." 1965). Ancak tabloda AP milletvekillerinden Ahmet Can Bilgin'in yerellik durumu farklı görünmektedir. Buna karşın kendisi uzun yıllar Tavşanlı Tunçbilek işletmelerinde mühendis olarak çalışmakta ve halkın büyük sempatisi ile karşılanmaktadır. Dolayısıyla nüfusa kayıt anlamında Kütahyalı olmasa da uzun yıllar yaşadığı bölge olması bakımından yerel siyasetçi olarak kabul edilebilir. MP adayı ise genel merkezden gösterilen milli bakiye sisteminden seçilen bir isimdir. Kemal Kaçar daha sonra AP'ye katılacaktır. Böylece AP XIII. dönem mecliste 5 milletvekili ile temsil edilmiş olacaktır. Bu dönem açısından bakıldığında Kütahya parlamentoda yerel adayların çoğunlukta olduğu bir temsile sahiptir.

Tablo 9: 1965 Kütahya Milletvekili Eğitim

\begin{tabular}{ccccc}
\hline Eğitim Seviyesi & AP & CHP & MP & Genel Oran \\
\hline \multirow{2}{*}{ Lise, İdadi, Sultani, Kolej, Meslek Okulu } & 2 & - & 1 & 3 \\
Üniversite & 50,0 & - & 50,0 & 50,0 \\
& 2 & 1 & - & 3 \\
Toplam & 50,0 & 100,0 & - & 50,0 \\
& 4 & 1 & 1 & 6 \\
\hline
\end{tabular}

XIII. Dönem Kütahya milletvekilleri profilinde lise ve üniversite eşit dağılma sahiptir. Üniversite mezunları hukuk kökenli olup bir lise mezunu vekil (AP, Mehmet Ersoy) hukuk fakültesi terktir. Ayrıca bir de maden mühendisi bulunmaktadır. Hukuk fakültesi Türkiye'de siyasi elit yetişmesi bakımından önemli alanlardan biridir. Ayrıca 1960 sonrası özellikle AP dönemi ile birlikte artan mühendislik yatırımları neticesinde mühendislik fakültelerinin de siyasi elit yetiştirilmesi bakımından önemli bir yeri bulunmaktadır. Bu dönemde hukuk ve tıp alanları yanında mühendislik artan bir mesleki öneme sahiptir. Mühendislik fakülteleri bu anlamda sonraki yıllarda Süleyman Demirel, Turgut Özal, Necmettin Erbakan gibi siyasi liderlerle başbakanlar çıkartarak siyasi aktörlerin yetişmesine kaynaklık edecektir. 
Tablo 10: 1965 Kütahya Milletvekili Meslek

\begin{tabular}{ccccc}
\hline Meslek* & AP & CHP & MP & Genel Oran \\
\hline İdare/Bürokrat & 1 & - & - & 1 \\
& 16,7 & & - & 10,0 \\
Maliye & 1 & - & 1 & 1 \\
& 16,7 & - & 50,0 & 2 \\
Ticaret & 1 & & 1 & 20,0 \\
& 16,7 & - & 50,0 & 2 \\
Tüccar & 1 & - & - & 1 \\
& 16,7 & 1 & - & 10,0 \\
Mühendis & 1 & 50,0 & & 1 \\
Hukukçu & 16,7 & 1 & & 2 \\
Belediyecilik & - & 50,0 & & 20,0 \\
\hline
\end{tabular}

* Mesleklerdeki rakamlar birer kişiyi temsil etmemektedir. Bir milletvekili birden fazla mesleki statüye sahiptir. Oranlar buna bă̆ll olarak değerlendirilmektedir.

Mesleki dağılım incelendiğinde idare/bürokrat ve ticaret/tüccar eğilim ön plana çıkmaktadır. Ticaret/tüccar genel anlamda ortak bir özelliği sergilemektedir. Kütahya özelinde geçmiş seçimler de göz önüne alındığında yerel eşrafa dayalı olmak oldukça önemlidir. Bunun yanı sıra belediye başkanlıkları parlamentoya geçmek için önemli bir statü görevi görmektedir. Merkez siyasete geçiş için çevresel bir siyasi faktör niteliği taşımaktadır. Aynı şekilde alanında yetkin bir akademik faaliyet siyasetin kurumsal örgütlenmesinde söz söyleme imkânı tanıyarak parlamentoda yer almayı sunmaktadır.

\section{1969 Milletvekili Genel Seçimleri ve Kütahya}

1969 seçimlerinin en dikkat çeken yanı seçimlere katılan parti sayısındaki fazlalıktır. Türkiye'nin siyasal yapısındaki ideolojik ayrımlar netleştikçe siyasal partilerin sayısı da artmaktadır. Bu partilerin birçoğu ilk defa genel seçimlere katılacaklardır. Güven Partisi (GP), CHP içinde ortanın solu tartışmaları neticesinde ayrılan ekibin kurduğu bir partidir. Yine Birlik Partisi (BP), alevi kitlelerini temsil etmek amaciyla kurulmuş bir partidir. Ayrıca Alpaslan Türkeş liderliğinde CKMP adıyla devam eden siyasal parti Milliyetçi Hareket Partisi (MHP) ismi altında siyasal hayatına yön vermiştir.

Türkiye 1960'lı yılların sonuna doğru ideolojik olarak çeşitli kamplara ayrılmaya başlamıştır. Demokratlar ve Halkçılar arasındaki 1960 öncesinde meydana gelen tartışmalar yeni dönem tartışmalarının yanında oldukça sönük kalmaktadır. Siyasal tartışmalar artık parlamento ve partililer arasında değil sokaklarda karşılık bulmaktadır. Örneğin; 16 Şubat1969 tarihinde taksimde yapılan işçi yürüyüşü sağ ve sol çatışmasına dönüşmüştür. Tarihe "Kanlı Pazar" olarak geçen olaylarda iki kişi hayatını kaybetmiş olup onlarca insan yaralanmıştır ("Taksimde Arbede", 1969). 1969 seçimleri öğrenci hareketleri, grevler, içeride üniversite olayları ve silahlı mücadelelere sahne olan toplumsal olaylar arasında gerçekleştirilmiştir ("Öğrenciler Bütün”, 1969). CHP söylemini daha sola kaydırırken, sağda da milliyetçi, İslamcı, merkez sağ partiler arasındaki ayrımlar netleşmektedir. Böylesine ekonomik/siyasal koşulların ağırlaştığı bir ortamda 12 Ekim 1969 tarihinde milletvekili genel seçimleri gerçekleştirilmiş oldu. Seçimler bir önceki seçim sistemi olan milli bakiye sistemi yerine d'hont seçim sistemiyle gerçekleştirildi. Ülke genelindeki işçi ve öğrenci hareketleri, soldaki devrim beklentisi ve sağda komünizmle mücadele/komando birlikleri arasındaki attan gerilimlere karşın Türk toplum yapısı büyük oranda kırsal üretim ilişkilerine dayanmaktadır. Dolayısıyla büyük kent merkezlerindeki makro siyasal gelişmelerin Anadolu kentlerinde yansımaları önem arz etmektedir. Kütahya 1969 yılı itibariyle 7 ilçe, 14 bucak ve 616 köy ile 398.081 nüfusa sahiptir. Nüfusun 197.127'si kadın, 200.954 ‘ü 
erkektir. Şehir nüfusu 87.084 olup köy nüfusu 310.997 'dir. Sigortalı işçi sayısı 17.289'dir (Erinç, 1969). İşçi sayısı oranı görüleceği üzere köy nüfusunun \%17'sine denk gelmektedir. Dolayısıyla şehirlerde makro siyaseti yönlendiren aktörler (işçiler, öğrenciler, aydınlar) sayısal azınlığa karşın eylemsel/yönetsel güçlerinden ötürü medya ve devlet bürokrasisi gibi güç aygıtları vasıtasıyla gündemi üretme hakkına da sahiptirler. Ancak bu tartışmaların Anadolu kentlerinde aynı karşılığı görmesi mümkün görünmemektedir. Kütahya'da eğitim seviyesi göz önüne alındığında şehirde okuma bilenlerin oran1 \%68,07, köyde okuma yazma bilenlerin oranı ise \%37,95'tir (Erinç, 1969). $\mathrm{Bu}$ oranlar da sosyalizm, faşizm gibi ideolojik tartışmalara katılım noktasında Anadolu'nun ve köylünün mümkünlüğünü ortaya koymaktadır. Köylerde 74.664 çiftçi ailesi yaşamaktadır. Bunlardan 23.330'unun toprağı bulunmamaktadır. Ayrıca \%31,9'un toprağı yoktur. Toprağı bulunmayan ailelerden 23.489'u tarım işçiliği, diğer kısmı ise ortakçılıkla geçinmektedir. Ayrıca 91 orman içi köyünün nüfusu 31,509 olup, orman kenarında bulunan 174 köyün nüfusu da 96,294'tür. Toprak genişliği 6-10 dönüm arsında bulunan arazi işletmelerinin oranı \%14, 11-25 dönüm arasında toprağı bulunan sahanın oranı \%11,6'dır. 200 ve üzeri dönüm ve toprağa sahip işletmelerin oranı ise \%0,8'dir (Erinç, 1969). Görüleceği üzere Kütahya'da büyük boy toprak sahibi aile bulunmamakla birlikte büyük oranda köye dayalı kırsal bir üretim ilişkisine dayanmaktadır. Dolayısıyla işçi hareketleri tartışma konuları arasında önemli bir yer almamaktadır. Kentlerde tartışılan ortanın solu gibi ideolojik söylemler şehirde yer bulmadığı gibi kentin önde gelen sendika liderleri de CHP'nin dahi gelip kendilerine ortanın solu ile ilgili bir malumat vermediğini, ilde toplantı yapılmadığını belirtmektedirler. Ayrıca işçilerin çoğunluğunun ise TİP veya CHP'li değil AP'li olduğu görülmektedir (“Kütahya'da bir”, 1969). Kütahya'dan gösterilen adaylar şu isimlerden oluşmaktadır: AP: Mesut Erez, Kemal Kaçar, İhsan Ersoy, Mehmet Ersoy, İbrahim Ertem. CHP: Ali Erbek, A. Haşim Benli, Ahmet Güner, Veliyiddin Sindel, Ali H. Korkmaz., Osman Ertokuş. TïP: Sabri Basan, Âdem Çiftçi, Hüseyin Işık. MP: Abdülkadir Gürol, Tahsin Aktürk. MHP: Sadrettin Tosbi, Osman Nesimi Yavuz, Rıfat Gürpınar, Kâmil Özkan, Necati Tepe, Necati Çağırıcı. GP: Hikmet Erdoğmuş. BP: Halil Sönmez. Hüseyin Cilay ("Parti Adaylarının", 1969).

Tablo 11: 1969 Milletvekili Genel Seçimi Kütahya İli Sonuçları

\begin{tabular}{|c|c|c|c|c|c|c|c|c|c|}
\hline \multicolumn{10}{|c|}{1969 Milletvekili Genel Seçimi Kütahya İli Sonuçları } \\
\hline $\begin{array}{c}\text { Seçim Çevresi } \\
\text { Ve İlçe }\end{array}$ & $\mathbf{A P}$ & CHP & GP & MP & MHP & BP & TíP & YTP & Băğımsız \\
\hline Kütahya & $\begin{array}{c}72.406 \\
61,0 \\
5 \mathrm{Mv} .\end{array}$ & $\begin{array}{c}25.440 \\
21,4 \\
1 \mathrm{Mv} .\end{array}$ & $\begin{array}{c}5.787 \\
4,9 \\
-\end{array}$ & $\begin{array}{c}4.673 \\
3,9 \\
-\end{array}$ & $\begin{array}{c}4.095 \\
3,5 \\
-\end{array}$ & $\begin{array}{c}3.552 \\
3,0 \\
-\end{array}$ & $\begin{array}{c}1.494 \\
1,3 \\
-\end{array}$ & - & $\begin{array}{c}1.208 \\
1,0 \\
-\end{array}$ \\
\hline Altıntaş & $\begin{array}{c}4.097 \\
47,6\end{array}$ & $\begin{array}{c}2.027 \\
23,5\end{array}$ & $\begin{array}{c}442 \\
5,1\end{array}$ & $\begin{array}{l}989 \\
11,5\end{array}$ & $\begin{array}{l}573 \\
6,7\end{array}$ & $\begin{array}{c}331 \\
3,8\end{array}$ & $\begin{array}{c}108 \\
1,3\end{array}$ & - & $\begin{array}{l}40 \\
0,5\end{array}$ \\
\hline Domaniç & $\begin{array}{c}3.594 \\
63,6\end{array}$ & $\begin{array}{c}1.342 \\
23,7\end{array}$ & $\begin{array}{c}256 \\
4,5\end{array}$ & $\begin{array}{l}208 \\
3,7\end{array}$ & $\begin{array}{c}101 \\
1,8\end{array}$ & $\begin{array}{l}78 \\
1,4\end{array}$ & $\begin{array}{c}51 \\
0,9\end{array}$ & - & $\begin{array}{l}25 \\
0,4\end{array}$ \\
\hline Emet & $\begin{array}{c}8.236 \\
59,9\end{array}$ & $\begin{array}{c}2.580 \\
18,7\end{array}$ & $\begin{array}{l}780 \\
5,7\end{array}$ & $\begin{array}{c}801 \\
5,7\end{array}$ & $\begin{array}{l}576 \\
4,2\end{array}$ & $\begin{array}{c}516 \\
3,8\end{array}$ & $\begin{array}{c}206 \\
1,5\end{array}$ & - & $\begin{array}{l}56 \\
0,4\end{array}$ \\
\hline Gediz & $\begin{array}{c}11.206 \\
63,8\end{array}$ & $\begin{array}{c}3.249 \\
18,5\end{array}$ & $\begin{array}{c}1.014 \\
5,8\end{array}$ & $\begin{array}{c}695 \\
4\end{array}$ & $\begin{array}{l}420 \\
2,4\end{array}$ & $\begin{array}{c}492 \\
2,8\end{array}$ & $\begin{array}{c}283 \\
1,6\end{array}$ & - & $\begin{array}{l}190 \\
1,1\end{array}$ \\
\hline Merkez & $\begin{array}{c}22.719 \\
65,1\end{array}$ & $\begin{array}{c}6.319 \\
18,1\end{array}$ & $\begin{array}{c}1.630 \\
4,7\end{array}$ & $\begin{array}{l}954 \\
2,7\end{array}$ & $\begin{array}{c}1.436 \\
4,1\end{array}$ & $\begin{array}{c}1.334 \\
3,8\end{array}$ & $\begin{array}{c}349 \\
1,0\end{array}$ & - & $\begin{array}{l}153 \\
0,5\end{array}$ \\
\hline Simav & $\begin{array}{c}9.541 \\
56,1\end{array}$ & $\begin{array}{c}4.031 \\
23,7\end{array}$ & $\begin{array}{c}867 \\
5,1\end{array}$ & $\begin{array}{c}604 \\
3,6\end{array}$ & $\begin{array}{c}582 \\
3,2\end{array}$ & $\begin{array}{c}448 \\
2,6\end{array}$ & $\begin{array}{c}254 \\
1,5\end{array}$ & - & $\begin{array}{l}678 \\
4,0\end{array}$ \\
\hline Tavşanll & $\begin{array}{c}13.013 \\
61,4\end{array}$ & $\begin{array}{c}5.895 \\
27,8\end{array}$ & $\begin{array}{l}798 \\
3,8\end{array}$ & $\begin{array}{r}422 \\
2,0\end{array}$ & $\begin{array}{r}407 \\
1,9\end{array}$ & $\begin{array}{c}353 \\
1,1\end{array}$ & $\begin{array}{c}243 \\
1,1\end{array}$ & - & $\begin{array}{r}66 \\
0,3\end{array}$ \\
\hline
\end{tabular}


Ülke genelinde seçimleri AP kazandı (“AP İktidarda”, 1969). Geçen seçimlerde DP mirasına sahip olan AP, Kütahya'da sağ parti liderliğini de süreklilik haline getirdi. Tüm seçim bölgelerinden birinci parti olarak çıkmayı başardı. CHP, Güven Partisi'nin ayrılmasıyla özellikle muhafazakâr şehirlerde güç kaybetmektedir. GP'nin ortanın sağında olan Halk Partililerin dışında bir tabana yaslanamayacağı görülmektedir. CHP'nin oylarındaki düşüşte ayrıca alevi kitlelerin bir kısmının oylarını kapmayı başaran BP'nin seçimlere katılması etkili olmuştur. TİP Kütahya'da işçi çevrelerinden \%1,3 dolayında oy almayı başarmıştır. MP ise lideri Osman Bölükbaşı'nın siyasi karakteri ile belli bir oy oranında seyir göstermektedir.

Tablo 12: 1969 Kütahya Milletvekili Yaş Kategorileri

\begin{tabular}{cccc}
\hline Yaş Kategorileri & AP & CHP & Genel Oran \\
\hline \multirow{2}{*}{39 ve Altı } & 1 & - & 1 \\
& 20,0 & - & 16,7 \\
$40-49$ & 3 & 1 & 4 \\
& 60,0 & 100,0 & 66,7 \\
$50-59$ & 1 & - & 1 \\
& 20,0 & - & 16,7 \\
60 ve Üstü & - & - & - \\
& - & - & 6 \\
Toplam & 5 & 1 & 100,0 \\
Yaş Ortalamast & 100,0 & 100,0 & 44,00 \\
\hline
\end{tabular}

Türk milletvekillerin ortalama yaşı, Batı'daki çoğu yasa koyucunun yaşından biraz daha gençtir (Frey, 1965). Bu seçimlerde de Kütahya milletvekillerinin yaş ortalaması 44 ile genç bir görünüm sergilemektedir. Geçen parlamento döneminde bu oran 39 idi. Ancak bu seçimde artmıştır. Dört milletvekilinin arka arkaya ikinci parlamento döneminde seçilmiş olması bu oranın artışını beraberinde getirmiştir.

Tablo 13: 1969 Kütahya Milletvekili Yerellik

\begin{tabular}{ccccc}
\hline Yerellik & AP & CHP & Genel Oran \\
\hline \multirow{2}{*}{ Ayn } & 3 & 1 & 4 \\
& 60,0 & 100,0 & 66,7 \\
Farkl & 2 & - & 2 \\
& 40,0 & 1 & 33,3 \\
\multirow{2}{*}{ Toplam } & 5 & 100,0 & 6 \\
& 100,0 & 100,0 \\
\hline
\end{tabular}

1969 seçimleri itibariyle Kütahya'da yine yerel adaylar çoğunluktadır. AP iki adayı merkezden gelen adaylardır. Kütahya'nın sorunlarına hâkim bir profil ile devam edildiği görülmektedir. Ancak bu seçim döneminde partiler daha fazla merkezden aday çıkarmaya yönelmişlerdir. Çünkü siyasal partiler güç kazandıkça büyük şehirlerde yaşayan ve modernleşen bireylerde hemşerilik duyguları azalır. Ankara, İstanbul gibi metropol kentler daha fazla aday hakkına sahip olsa da herkese yetmez. Bunun neticesinde Anadolu şehirlerinden aday göstermek durumunda kalınır. Bu durum ise Anadolu şehirlerinde bir temsil problemi doğurmaktadır. 
Tablo 14: 1969 Kütahya Milletvekili Eğitim

\begin{tabular}{cccc}
\hline Eğitim Seviyesi & AP & CHP & Genel Oran \\
\hline Ortaokul & - & 1 & 1 \\
& - & 100,0 & 16,7 \\
Lise, İdadi, Sultani, Kolej, Meslek Okulu & 2 & - & 2 \\
Üniversite & 40,0 & - & 33,3 \\
& 3 & - & 3 \\
Toplam & 60,0 & - & 50,0 \\
& 5 & 1 & 6 \\
\hline
\end{tabular}

Üniversite mezunlarının Kütahya'da oranı seçimlerde yerleşiklik almaktadır. Hukuk fakültesi ise yine bu seçim döneminde öne çıkan disiplin olarak dikkat çekmektedir. Kütahya'dan milletvekilliğine giden yolda tüccarlığa dayalı eşraf ve hukuk mezunu bürokrat olmak önemli bir kıstas olarak görünmektedir. Önceki seçimlerde ortaya çıkan sonuçların devam ettiği görülmektedir.

Tablo 15: 1969 Kütahya Milletvekili Meslek

\begin{tabular}{cccc}
\hline Meslek* & AP & CHP & Genel Oran \\
\hline İdare/Bürokrat & 1 & - & 1 \\
Maliye & 10,0 & 1,7 & 2 \\
Ticaret & 10,0 & 1 & 15,3 \\
Tüccar & 1 & 33,3 & 2 \\
Hukukçu & 10,0 & 1 & 15,3 \\
& 1 & 33,3 & 1 \\
Tekniker & 10,0 & - & 7,7 \\
Mimar & 1 & 33,3 & 2 \\
Belediyecilik & 10,0 & & 15,3 \\
& 1 & & 1 \\
& 10,0 & & 7,7 \\
\end{tabular}

*Mesleklerdeki rakamlar birer kişiyi temsil etmemektedir. Bir milletvekili birden fazla mesleki statüye sahiptir. Oranlar buna bağlı olarak değerlendirilmektedir.

Ticaret/tüccar, hukuk, mimar ve bürokratik kadrolar yine Kütahya'da milletvekili profilinin oluşmasını sağlayan temel mesleki formasyonu üretmektedir. Kanaat önderleri veya kentin seçkinleri arasından iş dünyasının büyük isimlerinin siyasete doğrudan katılmadığı görülmektedir. Belediyecilik de yine bu dönem vekilleri arasında parlamentoda yer alabilmek için önemli bir statü geçişi özelliği sağlamaya devam etmektedir.

\section{Sonuç}

Siyasal parti alanında çalışma yapmak makro ve mikro arasındaki dengeyi de kavrama üzerine kuruludur. Ülke düzeyinde merkezi siyasetin gerilimleri çevreye indikçe etki alanını konunun ehemmiyetine göre gevşetmektedir. Dolayısıyla merkezi sorunlardan hareketle çevreyi anlama çabası bazı durumlarda yetersiz kalmaktadır. 1960'lı yılların öğrenci hareketleri liderleri Anadolu'ya devrim iddiası ile geçtiklerinde böylesine bir alan dışılıkla karşıllaştılar. Alan dışılıktan kasıt şudur: Sosyalizm gibi teorik yoğunluğu ve praksis bağlamda yoğun eylemsellik içeren doktrinlerin taşıyıcıları da aynı oranda donanıma sahip olmak durumundadırlar. Oysaki Anadolu'nun pek çok orta büyüklükteki muhafazakâr kentlerinde benzer ilgiler/donanımlar 
mevcut değildir. Bu sebeple köylü devrimi gerçekleştirmek veya devrime köylü desteği sağlamak maksadıyla Anadolu'ya geçildiğinde köylülerin ihbarı ile karşılaşılmıştır. Yine şehirlerdeki işçi hareketlerinin medyada çokça yer bulmasına karşın Anadolu şehirlerinde aynı oranda oya dönüşmemesi, işçi partilerine değil muhafazakâr partilerine oy verilmesi geleneksel/kültürel yapının sınıfsal yapılara nazaran ön planda olmasıyla alakalıdır. Kütahya orta büyüklükte bir Anadolu şehri olarak, geleneksel/muhafazakâr kodlara yaslanarak bu duruma örneklik teşkil eder. 1946 sonrasında DP ile kurduğu geleneksel söylem iktisadi teşekküllerin kurulması ile birlikte ekonomik/kültürel bağa dönüşmüştür. 27 Mayıs ihtilali sonrasında bu bağ çözülmemiştir. 1961 Anayasasına büyük oranda hayır veren illerin başında yer almıştır. 1961 seçimlerinden itibaren DP'nin yerine hangi partinin ülke genelinde ve Kütahya özelinde alacağı tartışmaları 1965 seçimleri sonucunda netleşmiştir. 1960'lı yıllar boyunca Süleyman Demirel liderliğinde AP merkez sağın temsilcisi olma yolunda önemli başarılar elde etmiştir. Kütahya özelinde AP birinci parti konumuna geçerken CHP ise ikinci parti konumundadır. Bu anlamda 1946 sonrasında sağ temelli partiler ile kurulan diyaloğun 1970'li yıllara kadar artarak devam ettiği görülmektedir. Kütahya milletvekili profilinde hukuk mezunları ve ticaret/tüccara dayalı eşraf en dikkat çeken kesimi oluşturmaktadır. Ayrıca belediyecilikten gelmek parlamentoya seçilmek için önemli bir siyasi statüyü oluşturmaktadır. 1960'lı yıllardan sonra ise mühendislik de yine siyasi seçkincilik için önemli bir elit yetiştirme merkezidir. Fakat hemen belirtmek gerekir ki bu seçimler ve öncesinde kadın adaylar ve dolayısıyla kadın milletvekili bulunmamaktadır. Dezavantajlı grupların Kütahya siyasal parti merkezlerinde yeterince yer bulamadığı belirtilebilir. Kütahya'dan seçilen ilk kadın milletvekili 2018 seçimlerinde AK Parti'den seçimi kazanacak olan Ceyda Çetin Erenler'dir. Kütahya milletvekili profilinde erkek egemen bir eğilim dikkat çekmektedir. Sonuç itibariyle Kütahya'da 1960-1971 arası dönemde geleneksel/muhafazakâr/dini kültürel tabana yaslanan bir siyasal görünüm öne çıkmaktadır.

\section{Kaynakça}

Abadan, N. (1966). Anayasa hukuku ve siyasi bilimler açısından 1965 seçimlerinin tahlili. Ankara: Ankara Üniversitesi Siyasal Bilgiler Fakültesi Yayınları.

AP iktidarda. (1969, Ekim 13). Milliyet, s.1.

A.P.li bir kadın. (1961, Ekim 9). Milliyet, s.1.

AP'nin sembolü tartışma konusu oldu. (1965, Temmuz 21). Cumhuriyet, s.1.

A.P. açık hava mitingine önem veriyor. (1965, Eylül 23). Kütahya Ekspres. s.1.

A.P. ve C.H.P. kütahya'dan merkez aday koymayacak. (1965, Temmuz 29). Kütahya Ekspres, s.1.

Ayata, A.G. (1990). Kasabada politika ve politikacı. Toplum ve Bilim, (50), 97-110.

Bölükbaşı ve Gümüşpala'nın çatışması devam ediyor. (1961, Ekim 11). Milliyet, s.1-5.

C.H.P.'lier donmuş oylarına güveniyorlar. (1965, Eylül 23). Kütahya Ekspres. s..1.

C.K.M.P. köy ve kasabalarda çalışıyorlar. (1965, Eylül 23). Kütahya Ekspres. s.1.

Demirel AP genel başkanı oldu. (1964, Kasım 30). Cumhuriyet, s.1.

Düşmanlık yok kardeşlik var. (1961, Ekim 9). Milliyet, ss.1-5.

Erinç, O. (1969, Eylül 14). Bütün yönleri ile iller. Cumhuriyet. s.5.

Frey, W. F. (1965). The turkish political elite, Cambridge: MIT Press.

F.r.zorlu ve h. polatkan dün sabaha karşı idam edildiler. (1961, Eylül 17). Yeni Ístanbul, s.1.

Göktürk, G. (2012). 1946-1980 yılları arasında siyaset sosyolojisi açısından Cumhuriyet Halk Partisi, Yayımlanmamış doktora tezi,İstanbul Üniversitesi, İstanbul. 
Göktürk, G. (2013). Kütahya'da 1946-1960 yılları arasında milletvekili genel seçimlerinin analizi ve siyasal yapı. Dumlupınar Üniversitesi Sosyal Bilimler Dergisi, (37), 253-266.

İlimizdeki siyasi parti adaylarının isimlerini bildiriyoruz. (1961, Eylül 23). Kütahya Ekspres, s.2. İlimizin kat'i seçim neticeleri. (1961, Ekim 19). Kütahya Ekspres, s.2.

Kili, S. (1976). 1960-1975 döneminde CHP'de gelişmeler, siyaset bilimi açısından bir inceleme, İstanbul: Boğaziçi Üniversitesi Yayınları.

Kimler seçildi. (1961, Ekim 20). Kütahya Ekspres, s.1.

Kuruluşundan günümüze Kütahya belediye başkanlart. (2021, 8 Mart). Erişim adresi: https://www.kutahya.bel.tr/belediyebaskanlari.asp

Küçükömer, İ. (2007). Batılılaşma, düzenin yabancılaşması, İstanbul: Bağlam Yayıncılık.

Kütahya'da AP. (1965, Ekim 11). Kütahya Ekspres, s.1.

Kütahya'da bir yaz gecesi. (1969, Eylül 14). Cumhuriyet, s.5.

Menderes de idam edildi. (1961, Eylül 18). Hürriyet, s.1.

Millet partisi seçimde netice almak için çalışıyor. (1965, Eylül 23). Kütahya Ekspres. s.1.

Milli anlaşma imzalandı. (1961, Eylül 6). Milliyet, s.1.

Nebioğlu, Z. (1965, Eylül 28). Nerede ne olabilir. Cumhuriyet, s.4.

Netice: evet yüzde 65 hayır yüzde 35. (1961, Temmuz 11). Cumhuriyet. s.1-5.

Öğrenciler bütün gün savaşa hazır bekledi. (1969, Mart 18). Milliyet. s.1.

Parti adaylarının listesi. (1969, Eylül 2). Cumhuriyet. s.5.

Parti liderleri gezisi başladi. (1961, Eylül 1961). Milliyet, s.1.

Partiler adaylık için yurda dağıldı. (1961, Eylül 7). Milliyet, s.1.

Seçim kampanyasına gelemedi. (1965, Ekim 8). Kütahya Ekspres. s.1.

Senatörlüğü CKMP adayları kazand1. (1961, Ekim 18). Kütahya Ekspres, s.1.

Sevik, N. (1961, Eylül 23). Kütahya'da DP'liler bir parti arıyor. Milliyet, ss.1-3.

Seyitömer termik santrali için konuşan yok. (1965, Eylül 23). Kütahya Ekspres. s.1.

Şehrimiz siyasi partilerin seçim propagandaları köyden merkeze sloganı ile devam ediyor. (1965, Eylül 22). Kütahya Ekspres. s.1.

Taksimde arbede: 2 ölü, 114 yaralı var. (1969, Şubat 17). Milliyet, s.1.

TBMM Temsilciler Meclisi Tutanak Dergisi, (1961). Cilt 6. toplantı 1, birleşim 80. ss. 83.94.

TBMM Tutanak Dergisi, (1965). Cilt 35. toplantı 4, birleşim 44. ss.132-181.

Tebliğin metni. (1961, Eylül 5). Milliyet, ss.1-5.

Türkeş başkan seçildi. (1964, Ağustos 1). Cumhuriyet, s.1.

Y.T.P. her partiden bir şeyler koparmaya çalışıyor. (1965, Eylül 23). Kütahya Ekspres. s.1. 